\title{
Implementing an augmented reality and animated infographics application for presentations: effect on audience engagement and efficacy of communication
}

\author{
Stella Doukianou ${ }^{1} \cdot$ Damon Daylamani-Zad $^{2}$ (D) $\cdot$ Kathy O'Loingsigh $^{1}$
}

Received: 30 April 2020 / Revised: 27 January 2021 / Accepted: 14 April 2021 /

Published online: 29 May 2021

(C) The Author(s) 2021

\begin{abstract}
Presentations are the most successful and popular form of communication in business. However, the formats of presentations in business have not changed much for past few decades. The emergent and disruptive technologies such as Augmented Reality and Animated Infographics have provided potential for enhancing communications in businesses to increase engagement and therefore increasing the effectiveness of such communications. This paper focuses on the impact and effectiveness of using interactive AR in business presentations. The paper presents the design and development of our AR presentation application. Followed by a presentation of an empirical study into the usability and effectiveness of using Augmented Reality and Animated Infographics in business presentation and compares the results against the traditional slideware slides presentation approach. The results of the experiment with 94 participants are presented and analysed. The results demonstrate that the AR approach out performs the traditional methods in terms of usability, audience engagement and effectiveness of communication.
\end{abstract}

Keywords Mixed/augmented reality · Business presentation ·

Empirical studies in visualization · Usability testing · Human computer interaction (HCI)

\section{Introduction}

Presentations are considered to be the most popular form of communication in businesses $[1,72,76]$. Industry executives use presentation as a standard practice to make stronger

Damon Daylamani-Zad

Damon.Daylamani-Zad@brunel.ac.uk

Stella Doukianou

S.Doukianou@greenwich.ac.uk

1 School of Computing and Mathematical Sciences, University of Greenwich, London, UK

2 College of Engineering, Design and Physical Sciences, Brunel University London, UB8 3PH, London, UK 
impact to their colleagues or clients than written communication and convey their messages effectively $[1,64]$. However, in most occasions this is not the case for traditional corporate business slideware presentations. The mis-communication and information loss after traditional slideware (PowerPoint) presentations due to lack of audience engagement or lack of an efficient method to present the information is an ongoing problem in corporate environments. Empirical evidence has shown that the majority of presentations fail to connect with their audience [38].

Presentations are useful at condensing information into the more relevant points, however it is important that the presenter does not compete with their slides for the audience's attention but instead exploit their benefits and expand on them [76]. Clear communication of information is important for effective and optimised functioning of businesses. A clear business proposal has a better chance at succeeding as they are quickly understood and are looked on in a more favourable light [57]. In preparation for a presentation, it is necessary to keep the audiences' focus by determining their background knowledge, the amount of time they have available, the time of day in which they are available and the setting of the presentation. Relating to the audience in this way can reveal the best practices in communicating with them [76]. Despite all the above, quite often, maintaining audience attention and engagement is a challenging task. According to [72] when oral presentation is accompanied by multimedia and good design, the message is conveyed in a stronger and more effective way.

Hence, there is a demand for more informative, influential, impressive and impactful presentation of information relevant to every part of business, including all departments and levels of hierarchy within these companies [57]. Since Augmented Reality (AR) has become another tool for visual presentation of information, it is now required to create new paradigms which support heads-up information presentation and interaction, seamlessly integrated with viewing and interacting with the real world $[19,80]$. Whilst there have been attempts for creating different presentation tools [20, 30, 31], there has been no attempt to use augmented reality as an interactive visualisation tool for presentations.

Towards addressing this challenge, this paper presents the findings of a usability and engagement study, which investigates the hypothesis; an AR interactive visualisation application would better support and engage users, compared to a traditional slideware presentation specially when incorporating animated infographics to enrich visualisation. An AR interactive information visualisation application was developed for Android Smartphones and tablets. The AR application included information about a corporate business, based in London U.K, where the information was visualised and suitably animated. In the study post-test scores were used to measure the application's usage effectiveness. In addition, a user engagement questionnaire was employed to compare audience engagement level when using the AR application against a control group with a standardised traditional slideware (PowerPoint) with the same information. Findings demonstrate that application of engaging animations and effective display of information in AR has a clear positive effect on increasing audience engagement when compared to traditional corporate slideware presentations.

In the following section, previous work related to this study is presented. Section 3 discusses the design and implementation of an AR application for business presentations. This is followed by the presentation of the methodology including the experiment design framework. Finally, the findings, limitations and future work are discussed. The discussion and conclusions reflect on the relevance of findings in terms of replacing traditional slideware presentations with a more interactive emergent approach. 


\section{Background and related work}

Many issues regarding current practice in corporate presentations is due to the dated methods. PowerPoint has slightly changed since it was published in 1984 and it does not fit within the new businesses surrounding by evolving technologies. Such technology was based on older methods which involved overhead projectors and slides with similar layout to PowerPoint slides called transparencies [84, 88]. Even though, today PowerPoint is the most common slideware application [40], there is an urgent need for corporate organisations to abandon outdated methods and replace them with engaging, well-designed and powerful presentation methods that are memorable, visual and simple without diluting the information [72].

The traditional slideware conventional presentation focuses on catering to the presenter rather than the audience. As a result there is poor communication of the content to the audience. The popular use of bullet points to summarise information has led to loss of information. This is a necessary bad-practice due to the lack of space for effective communication on a slideware slide that leads to the breaking up of information into arbitrary fragments, losing the contents' context and focus [8, 84, 88]. Shaw, Brown and Bromiley [77] demonstrate that the method of summarisation using bullet points results in vague, generic and uncertain information. Due to many of these issues, NASA reviewed their practices of using traditional slideware to communicate and present data and the Columbia Investigation board found that information was lost as it was filtered up the hierarchy, being summarised repeatedly through bullet points, poor information arrangement and design [29, 94]. On the contrary, visual-based presentations with few bullet-point text instead of wordheavy slides can allow for clearer, more engaging and effective presentations, which are vital to support well-made decisions in companies [58]. Empirical evidence on visuals used in presentations compared to text based slides shows that visuals are more effective and ensure audience agreement, attention and retention of memory [36].

\subsection{Visualisation in presentations}

Perception and cognition are key to successful visualisation design, as enough information should be provided to fully inform and satisfy the user [8,37]. Studies suggest that infographics are related to cognitive processes with benefits in working memory, information recall and retention and learning [11]. There is also evidence of graphical and visual based content stimulate working memory and aid learning [27, 56]. Visualisations of data exploit the perceptual and cognitive abilities of the audience to problem solve by presenting them with interactive visual portrayals of content [21,90].

Research has shown that engaging visual material improves audience attention $[11,21$, 56]. Visual representations such as diagrams, chart and infographics hold many advantages over standard data presentation by spreadsheet or report including; visuals aid for those who are not familiar with numbers as they make them more understandable. Additionally, data patterns and relationships are revealed that may not be seen if not represented visually. Graphs, as opposed to numbers, are able to engage with the audience and hold their attention with clear and visual portrayal [21, 48].

Display data in a cognitively efficient and visually appealing manner, such as using graphs and infographics, improves information communication and retention [49]. Screen size and capacity as well as the limits of human perception, limit the amount of information possible to display [75, 83]. Evidence has shown that humans process information in 
sequence, focusing on detail with a wider view of context for perspective $[3,71,89]$. Cognitive processes, when involved with graphic-based information communication methods and infographics, tend to be pre-attentive. As the visuals are initially perceived and viewed as a whole with details investigated following this, key aspects are grouped and regarded differently to each other $[3,95]$. Interactive animation is also a powerful method of informing as the data is processed cognitively as well as perceptually [34, 75, 91].

Visual-based design including images and exploiting vision as our most powerful sense is highly effective in attracting people's attention and improving the understanding and memory retention. Most presentations using slideware include a majority of text. Bulletpoint-based presentations fail to exploit the audience's ability to engage with visuals while simultaneously listening to the presenter's explanations and commentary, yet visuals are able to amplify the presenters dialogue. Visual cues are essential to direct the viewer to the key information. These in combination with structure allow for powerful storytelling which can effectively convey the message [72]. It is beneficial in presentations to use interesting visual devices, by adding something extra and unexpected, provided it is relevant to the key concept. This would enable the experience to become memorable, engaging and impactful $[35,76]$.

Visual material can be valuable as a reassuring prop for those less keen to take centre stage in presentations. Eyes can be more receptive to a message than ears. Visuals allow for a pause in commentary, which play an important part in presentations as it allows for audience to digest and absorb the information [64]. Visual and graphics in presentations must be informative, error free and accurate. The visceral reaction to presentation is significant in how the audience perceives the information. One of the most powerful visual stimuli is colour, which has the power to attract attention and affect the audience on an emotional level. Impactful imagery combined with effective storytelling can result in a compelling and successful presentation. Motion picture delivers this theory to an even greater extent, yet is currently underutilised in today's presentations. These are effective to give context to issues and illustrate solutions in a simple yet compelling manner.

\subsection{Animated infographics}

Animated infographics are a step further in the field of data visualisation, as they must include additional information and detail to fulfil the objective compared to static infographics. [56]. Animated infographics, also known as data videos, use the strength of storytelling to engage with the audience and communicate to them effectively. Animated Infographics combine data visualisations with visual and auditory stimuli to portray a data story [2].

In a study on animation used to present trends, it was found that the combination of animation, interesting data and an engaging presenter is effective in aiding the audience's comprehension of the data. It was also identified that this is the fastest, most efficient method of presentation and an enjoyable and memorable experience for the audience [2]. Movement and animation was deemed effective in emphasising key data and results, especially with live presentations as the presenter directs the audience's attention to an aspect before the animation starts, enforcing the concept further with commentary during the illustration. Animation is effective in showing changes in state and perspective as well portraying trends and how something works [73]. A benefit of animation is the ability to seamlessly build upon a visual gradually in a manner that the audience can easily follow. This can be a powerful tool in increasing audience comprehension and engagement. When an audience member loses track of the information, they will not be engaged for the remainder of the 
presentation while trying to catch up. Animated transitions, while having the risk of becoming distracting, if used appropriately and tactfully can be an entertaining and captivating aspect of a presentation [39].

Presentations aim to illustrate a concept and enable the audience to recall it. Visualisation's effect on memory is powerful and effective in this endeavour. Storytelling used with visualisation is a powerful tool, encouraging discussion and decision making as well as supporting process analysis [39]. The benefits of storytelling with infographics has been investigated and proven in studies in various fields including education [47, 68], corporate communication [74], scientific research [39], religious education [70] and sustainable development [32]. Several key concepts established throughout these researches include; the additional detail required in animated infographics, the sequential benefits of animated infographics, the engagement benefits of animated infographics and the power of storytelling in communication and engagement.

Kosara and Mackinlay [39] proposed the concept of storytelling affordances which describes the features used in visualisation which allow for narrative structure and guidance. The structuring of information whether linear or not can provide the audience with context and link key points together in a cohesive structure. Benefits of these methods include improved retention of information, interest, and engagement and therefore more informed choices and decisions. Features such as narrative or impressionable visuals that set presentations apart are key to making them memorable [39]. Narrative also impacts cognition and comprehension, two key factors to engagement in a successful presentation [68, 94].

\subsection{Interactive infographics}

Whilst interactive infographics seem complex, they provide a better experience to users. In contrast to static infographics which have little engagement, interactivity allows for a more interesting, user-focused, engaging and cognitively pleasant experience [49]. Interactive infographics require active involvement from the participants which ensures the participants' attention and engagement [56]. This form of infographics facilitates learning through visual means as well as participatory learning [22].

Interactive infographics allow the audience to view the data they wish at their own pace and in their own order. This helps them engage with the information as they focus on their interests and adapt the content to their needs, organising the dataset and aiding clarity [56]. Fixed information in static infographics limits the options available for the audience to interact with. Whilst the capacity for more information and capability for multiple views of this information can allow the user to connect with the content, filtering out aspects irrelevant to them will help them to focus more. Although using interactive infographics means independent navigation, there is still an option of using guidance if it benefits the narrative.

Both static and interactive infographics are increasingly popular online. Interactive infographics can also be used offline with many applications such as part of a software interface or on a kiosk dashboard [22]. Due to the increasing popularity of online media, the use of interactive infographics is starting to play an increasingly important role in news outlets [56]. Studies have shown that interactivity in infographics differ to static versions in user's perception as they are perceived to have a higher information quality [49]. Interactive infographics are structured more effectively and have a larger information capacity. The vertical format that static infographics are commonly designed in to accommodate smartphone screens and desktops, in which viewing is navigated by scrolling up and down the image, limits the perception of the content. As only one section can be viewed at a time, 
there is a loss of context. When viewed as a whole the text and graphics are often too small to be perceived, this issue as well as an overload of information leads to incomprehensible and over-complicated infographics. Whereas interactive infographics allow for layering of information and various views of the content, ensuring clarity while catering to context and detail [22].

\subsection{Augmented reality to increase engagement}

The benefits of immersion and an enhanced sense of reality in augmented reality (AR) technology has been implemented in many fields including construction, broadcasting, education, medical service, manufacturing, scientific research and architecture. Studies have shown that with the implementation of 3D models and augmented reality in construction drawings, recognition time is significantly improved, allowing for efficient evaluation [61].

Emerging technologies for creating immersive and engaging experiences have become popular in designing museum experiences. To avoid boredom and ensure enhanced visitor engagement, augmented reality tours as well as virtual reality experiences have been implemented in museums [63]. The immersive benefits of Augmented Reality have been used to preserve and promote cultural heritage in apps which overlay information and visualisations about monuments on the buildings when viewed through a smartphone. Similar systems exist in which geographical information is used for navigation purposes, highlighting nearby attractions and locations [17]. Augmented reality visualisations have also been used in research and education where phenomena which are not visible to the human eye can be evaluated and explored [96]. In marketing, AR has been used by sales teams to pitch to their clients. By holding target markers on plates, they can explain and promote their products without needing a sample, as AR superimposes a 3D model onto the plate [28, 97].

Low levels of interactivity in current learning methods result in a lack of engagement and AR was proposed as a solution. AR has the ability to improve student engagement and motivation as it appeals to its users individually. High levels of motivation and deep cognitive activity result in effective engagement with content, vital to learning and processing of information [28, 97].

Engagement is key to meaningful learning, it has been related to attention, interest, striving to achieve goals and time efficiency $[10,15,18,23,26,42,51,52,60,66,78]$. Whilst emergent technologies have the ability to draw attention, this must be used with the best practices of human cognition, behaviours and learning methods [14]. AR table top learning environments have been used to enhance lecture experiences and benefit the environment with improved attention and engagement of students. The combination of these various media which build upon traditional methods of information exchange give opportunity for a compelling learning environment in which information is portrayed with interaction and content can become more challenging to the audience. This method aims to improve the memory retention of students as well as their participation and consequently improve understanding of content with the aid of audio-visual augmentation.

AR's effective use of audiences' visual perception, auditory abilities as well as interactive preferences sets it ahead of traditional learning methods. Its digital format allows students to follow at their own pace and repeat sections if necessary. Lectures and demonstrations have been found to be one of the most effective forms of information exchange in the academia [45], the equivalent to this in the corporate world is identical in format - presentations.

Augmented Reality allows for easy navigation and understanding of large datasets displayed using 3D visualisations [82]. Augmented Reality visualisations aim to inform an audience about complex content in an efficient, engaging and interactive manner [6]. 
By exploiting perceptual and interactive capabilities, augmented reality can offer a more organic approach to working with data [5]. Visual representations allow for portrayal of different levels of detail and aspects of strategy in strategy visualisation [67].

\section{Animated infographics in AR for business presentations}

In order to take advantage of visual representation and augmented reality, an application was developed for the purpose of delivering a business presentation. The aim of the application was to deliver an engaging presentation which would captivate the audience and communicate effectively the information. The application was developed using Unity [86] and Vuforia AR [87]. Figure 1 illustrates screenshots of the app on a smartphone. This section presents the architecture, interaction design and implementation details of the app and the associated services.

The system consists of two high-level components: Backend Delivery Service and the AR application which consists of the Presenter app view and the Audience app view. Figure 2 presents the system architecture and interactions between various components of the implementation. The system uses a RESTful backend service to store and deliver presentations in the form of Unity Asset Bundles. The bundles includes all the assets graphical and textual, along with the animations and the scene where the presentation is developed in. This scene is packaged into an asset bundle and stored on the server hosting the service using POST and PUT requests. The AR app can access the service and request specific bundles using a GET request. This service was developed using C\# and Web API .Net. The architecture of this service is presented in Fig. 3.

\subsection{AR presentation: system architecture}

The presenter would create the presentation in Unity and once finalised, would package it as a unity asset bundle and upload it to the server as shown in Algorithm 1. If an existing presentation is being updated, then the Bundle_ID is used to replace (update) the previous asset bundle using a PUT request. If this is a new presentations, the asset bundle files are sent using a POST request to the Bundle CREATE sub-service which creates a new Bundle_ID and stores the asset bundle with its associated Bundle_ID on the server. Once the presenter is ready, they can start a presentation and if they do not have the assets on their device, they will be downloaded using the Bundle_ID. This process is presented in Algorithm 2. The audience members would join the presentation sessions and if the assets are not already on their
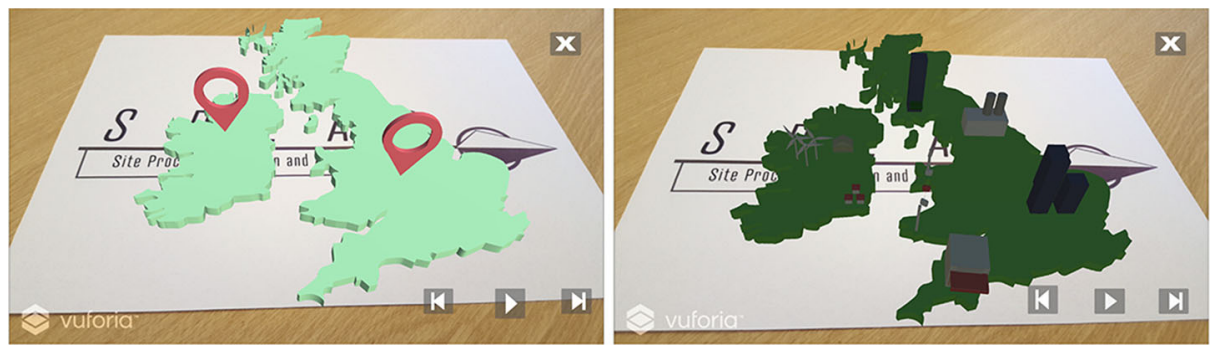

Fig. 1 Views from our Augmented Reality app on a smartphone; presenting company locations (top) and businesses across the UK (bottom) using animated infographics and AR 
device then the Bundle_ID of the session is sent to service and asset delivery commences. Algorithm 3 illustrates the process of joining a session as an audience member.

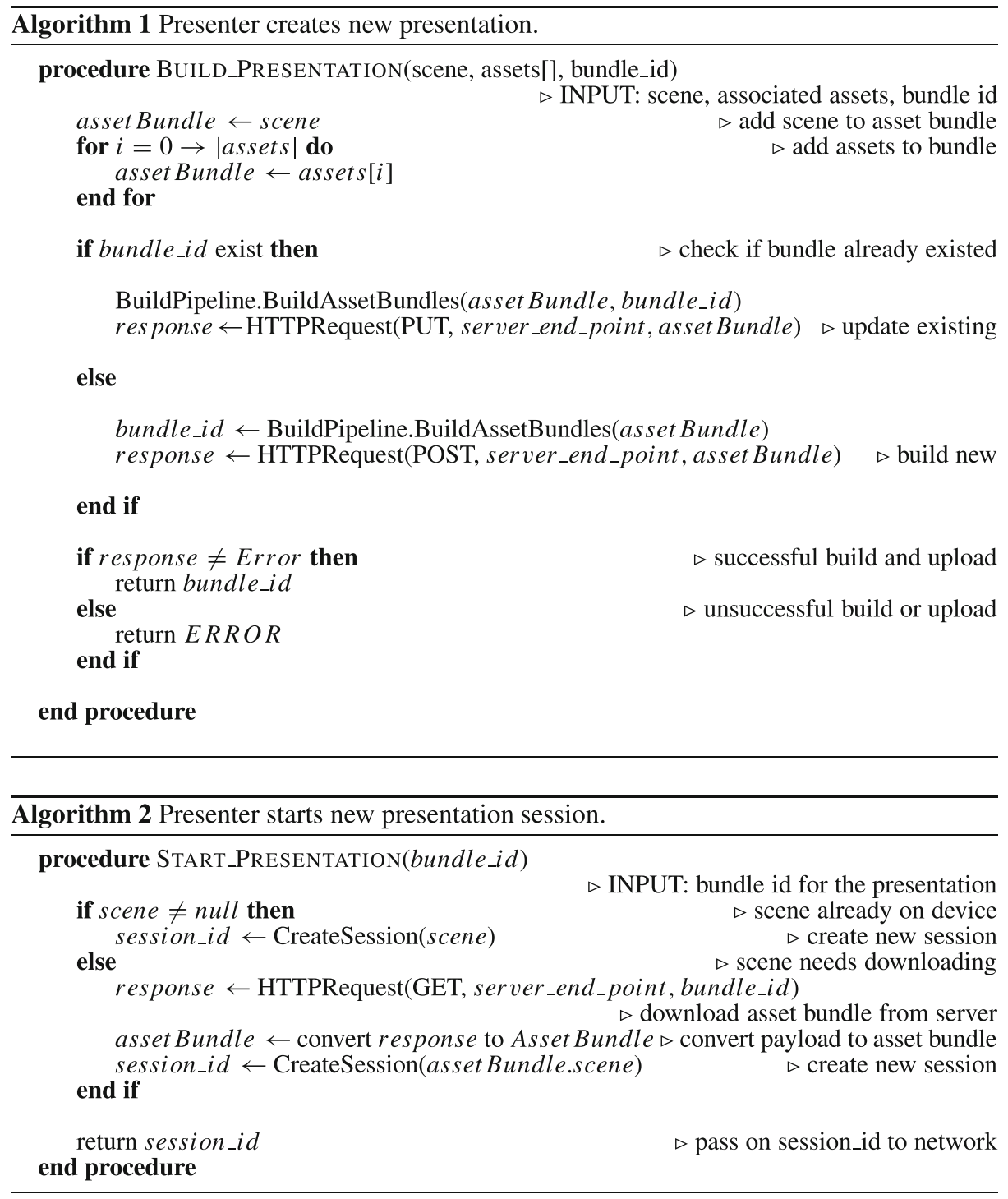

The app uses Unity multiplayer [85] to share the presentation state between the presenter and the audience members. The system follows a synchronised simultaneous simulation approach where each user, presenter and audience members, has all the assets and is running independently with a limited number of variables which are used to sync the sessions and commands which are communicated between presenter and audience members as RPC Commands. In this AR system the presenter would act as the server, whilst all audience members are clients in the session. The presenter would use the presenter view of the app and start a new presentation. If the assets already exist, the scene would initiate, if not the assets would be downloaded from the delivery service. Once a presentation has started, the 


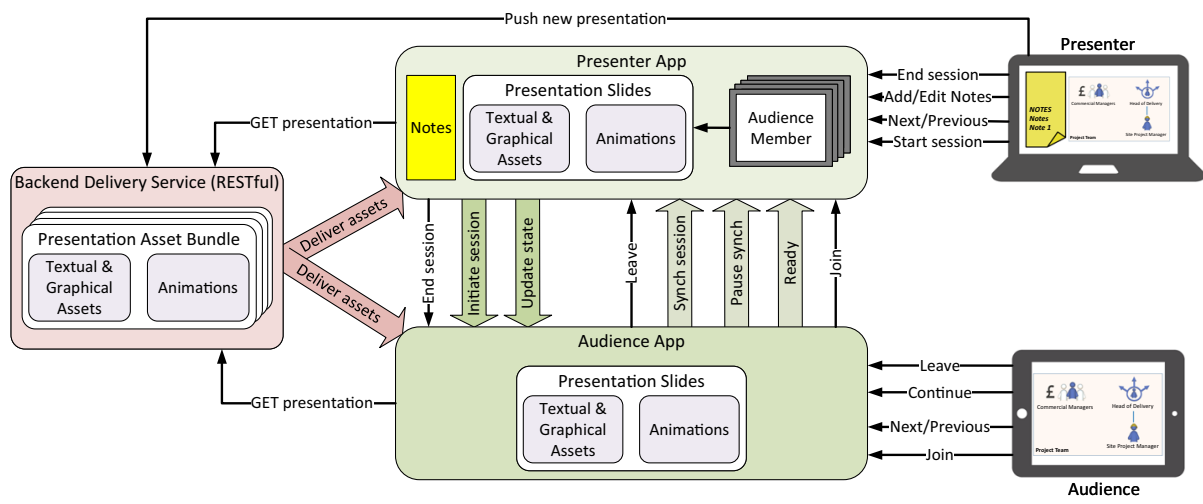

Fig. 2 System architecture of the AR app, presenting how different users would interact with the app and the communication between the apps from presenter view and audience view

audience can join using the marker and session ID provided by the presenter. The state of the presentation would be updated based on the actions on the presenter view (server). However, the audience can choose stay on a slide or check previous slides. This would pause the sync between the presenter and that specific audience. Once the audience member wants to re-sync with the session, they can do that by pressing the play button which would sync the state of their app with the current state of the presenter (server). Audience members can end the session by leaving. Once the presenter leaves and closes the presentation session, all audiences of the session will be notified and the presentation would stop.

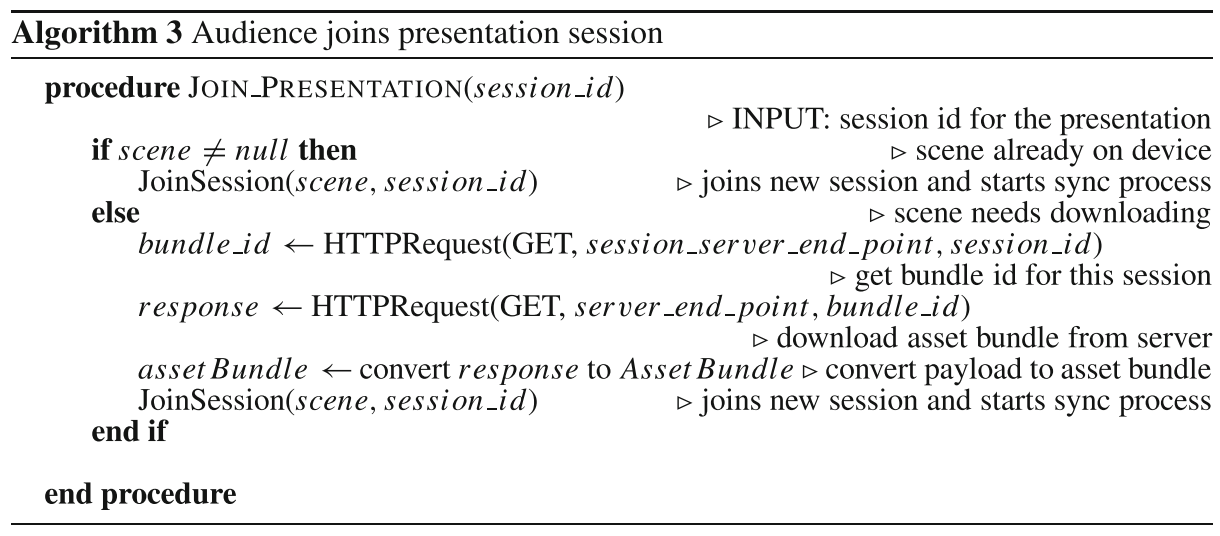

\subsection{AR App implementation}

The application was developed for Android smartphones and tablets, as well as PCs. The use of familiar platforms such as smartphones and PCs encourages users to try new tools, a familiar issue with professionals that have limited time and therefore less inclination to invest time in learning to use new technologies [24, 43]. The application worked with the use of target markers which the camera detect and the infographics appeared on the display. Figure 4 illustrates the view on the presenter view on a PC (left) and view on a smartphone (right). 


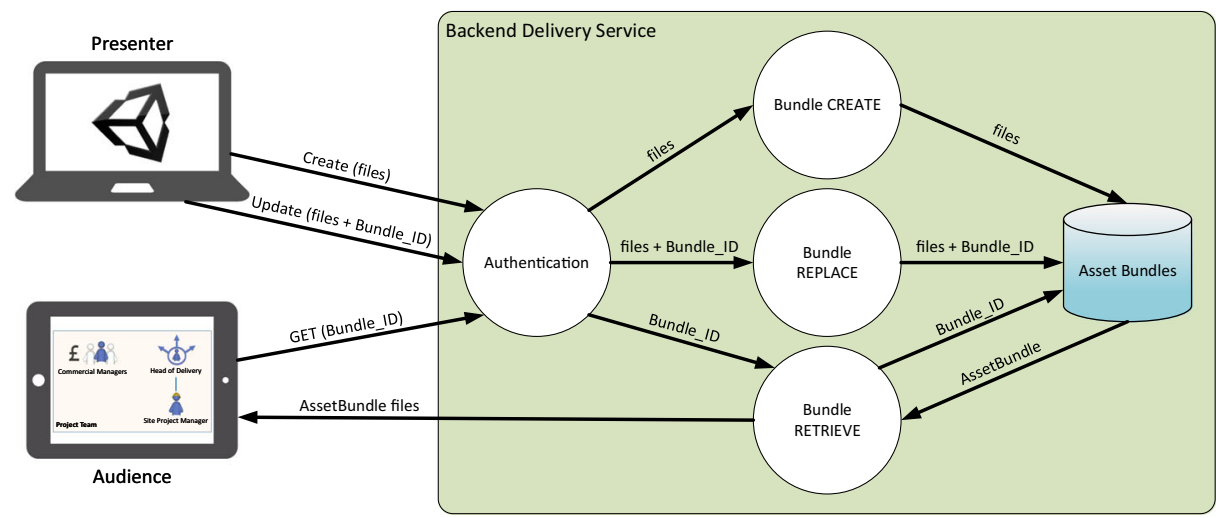

Fig. 3 RESTful backend service architecture: Asset Bundle Creation, Update and Delivery

The presentation in these examples and the experiment further included corporate information about the structure of the company, a standardised presentation that takes place in introduction meetings with internal and external staff. The first infographic includes an image of the United Kingdom along with the buildings which define the locations that the office are. Following 'slides' include information about the hierarchy and pie charts with the structure of the company.

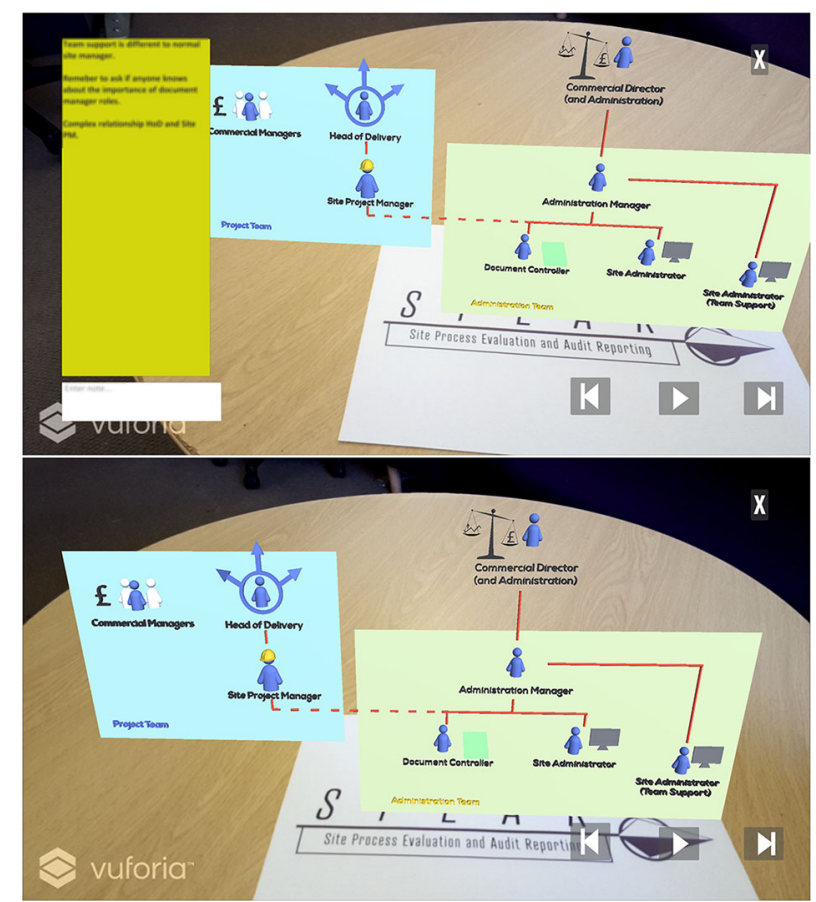

Fig. 4 AR presentation: PC view for the presenter machine (top), Smartphone view for an audience member (bottom) 


\subsection{Interaction and UI}

Navigation between animations and graphics was an important feature to allow users to revise the presentation and to follow along at their own pace $[39,56]$. This was implemented using UI buttons with familiar icons to denote next and previous, as the primary tool for exploration [65]. A play button was implemented which when used by presenter would replay the animation to help the presenter re-enforce a concept or repeat it. The play button on presenter view would allow the user to sync back with the presenter after pausing the sync. This feature helps users engage at their own pace and acts as a form of interaction [73]. Figure 5 illustrates the UI buttons and their functionality. These features along with the augmented reality 3D models as a form of interactivity itself, while users move around the models and graphs, were important factors to include in the application to improve understanding and discovery of relationships through exploration [5, 45, 54, 55, 65]. Interactive infographics are shown to improve engagement, interest and cognitive activity, as well as being perceived as a higher quality information portrayal in comparison to static infographics [49].

A text box and canvas, in the form of posted notes, was used to implement a note taking feature, beneficial to presenters as presentations often entail the collection of information over discussion and suggestions in addition to the information distributed during the presentation itself $[39,64]$. The note taking feature can be seen in the PC view on Fig. 4, this figure also demonstrates the placement of the buttons.

\subsection{Aesthetics: 3D models and infographics}

Infographics included in this presentation were of both purely graphical nature [9] or graphics accompanied by text [50]. Chart types included pie charts and hierarchy graphs developed with data supplied by the company as well as an organogram which was converted into 3D models for use in AR. It was important to keep the 3D aesthetically suitable and professional, as these factors in infographics have been shown to improve engagement and memorability [33]. Choice of colours was a key factor in the design process as colour in infographics has been found to impact memorability [12], and can help the audience link information and see relationships between graphs of similar colour [41, 79]. Appropriate

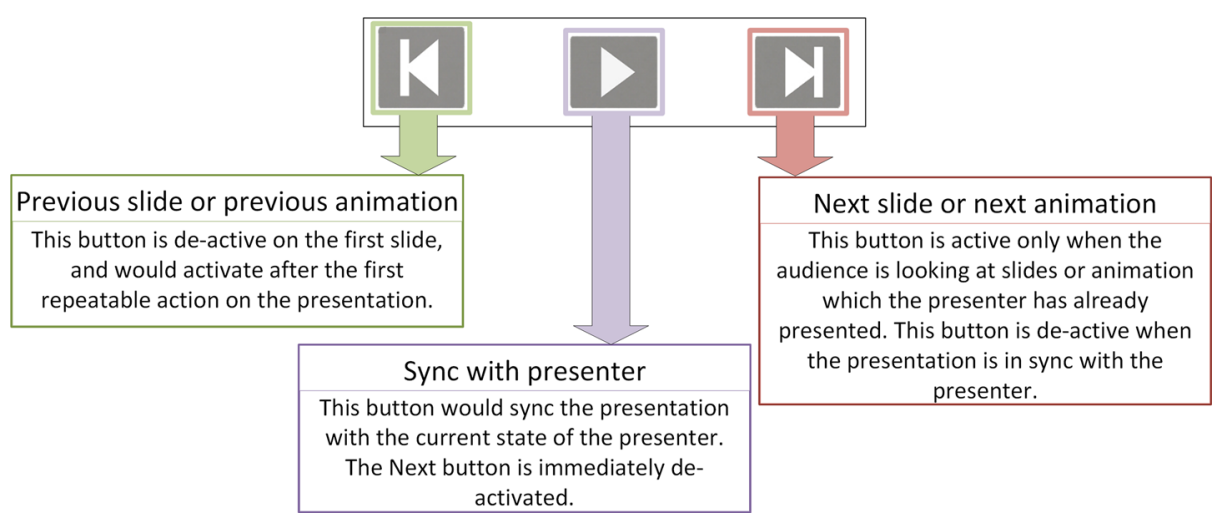

Fig. 5 UI menu which appear on the bottom right corner of the screen. The buttons use familiar icons to be intuitive 
colour choice has the power to make the infographics more appealing [33], to highlight important information and therefore improve understanding [53] as well as clarifying the infographic as a whole [79]. Thus, an appropriate colour palette was chosen to align the graphs in the presentation in terms of colour [16] which suited the professional setting as well as the branding of the company to avoid distraction and benefit the perception of the presentation $[72,76]$. Colours were chosen for data with the aim of portraying that they are all of equal importance and easily visible on a white background [79] or in the case of augmented reality a bright and well-lit background [4, 80].

\section{Engagement and usability of AR: an empirical study}

In order to evaluate the effect of the developed AR application, an experiment was designed to assess the usability, user engagement and effectiveness of communication (EoC) of the application in a real-world scenario against a traditional presentation as control. The experiment details are presented in this section.

\subsection{Design}

A quantitative research design was used which consisted of Post Study System Usability Questionnaire (PSSUQ) [44], User Engagement Scale (UES) questionnaire [92] and a post-study EoC test. PSSUQ would reveal application performance levels and UES would provide details on whether the AR presentation is able to keep audience's engagement more compared to a traditional slideware presentation.

The post-study EoC test, based around the presented topic, would be used to assess the effectiveness of communication. This test consisted of five questions devised based on the content of the presentation. The questions were devised based on the approach presented by [50] in order to evaluate the effectiveness of communication in presentations. The questions used were;

Q1) Where are the wind turbine projects located?

Q2) Name 4 sectors that the company works in?

Q3) What are the 4 cores of work Admin do?

Q4) Name 4 of the admin department roles.

Q5) Which area has the highest budget allocation?

Each questions was assigned four marks amounting to a total of twenty for a test. The response to Q1 and Q5 would be right/wrong answers and therefore can only be marked as 0 or 4 .

\subsection{Participants}

A total of 94 participants volunteered to take part in this experiment. Fifty professionals (25 female, 25 male) aged between 22 and $47(\mathrm{M}=34.78, \mathrm{SD}=8.137)$ years old participated in the Augmented Reality presentation (Group A). Forty four professionals between ages of 20 and $44(\mathrm{M}=33,23, \mathrm{SD}=7,628)$ took part in the traditional slideware presentation using PowerPoint (Control Group). Only 2 out of 50 participants in Group A did not have previous experience with AR and only 5 out of 44 participants in Control group did not have previous experience with AR. None of the participants in either group had used our AR tool before. The participants were recruited through the researchers' contacts form a company based in 
the United Kingdom. Participants (both AR group and Control group) had no prior knowledge of the topic and contents of the presentation as this was the orientation presentation for new employees.

\subsection{Materials}

The AR application presented in previous section was populated specifically with the material from corporate information about the structure of the aforementioned UK-based company. This is a standardised presentation that takes place in introduction meetings with internal or external staff of the company. The traditional slideware presentation included the exact same text, graphics (images, 3D models, colors) as our AR application. It did not include animation beyond the standard animations available in slideware tools. Figure 6 presents a sample slide in both AR and using traditional slideware. The same presenter was used for both groups. The presentation script, speech and interaction was identical. The Control group were provided with slide handouts and were able to browse through the slides similar to the AR Group.

\subsection{Procedure}

The experiment was divided into three phases: (1) Information sheets and consent forms, (2) Usability, Engagement testing and Effectiveness of communication of the AR application with Group A (3) Engagement testing and Effectiveness of communication for traditional slideware presentation with the control group. The experiment with AR group lasted 40

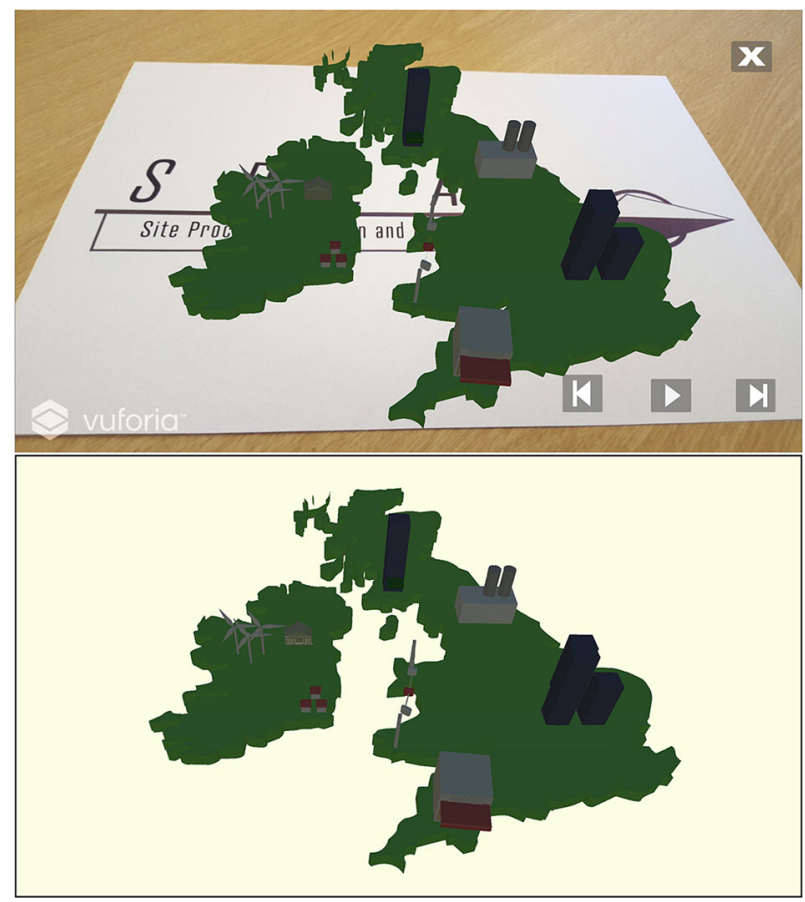

Fig. 6 Presenting company's businesses across the UK: in AR (top) and traditional slideware (bottom) 
minutes - 20 minutes for the presentation and $20 \mathrm{~min}$ for the questionnaires, whilst the experiment with the Control group lasted 30 minutes - 20 minutes for the presentation and $15 \mathrm{~min}$ for the questionnaire. Figure 7 summarises the procedure phases and the test taken by the participants.

At the beginning of the experiment, both groups were given a brief description of the project and consent forms to sign. In the second phase participants from Group A were directed to the room where the AR presentation took place. The room was a corporate meeting room with a large TV monitor for presentations which was connected to a laptop with the application loaded and displayed with the webcam feed and augmented reality on show. There were also phones with the app pre-loaded for each participant, as well as a number of printed target markers. The webcam connected to the laptop was directed at the presenter and target marker beside them placed on the table. The participants were asked to open the AR application and target the image on their desks. They started using the application along with the presenter. The setup of the experiment and the how groups shared the markers is illustrated in Fig. 8. When the presentation was completed, they were asked to fill in the PSSUQ questionnaire, the UES survey and the post-study EoC questions.

In the third phase, the control group was directed to a room where the traditional slideware presentation took place. After the end of the traditional slideware presentation, the participants filled the UES survey and the post-study EoC questions. If the participants were unclear about anything they were encouraged to ask the researchers for clarification at any point during the study.

\subsection{Data gathering for AR evaluation}

There are three different sources of data that were collected to evaluate the AR applications: 1) answers on the PSSUQ questionnaire 2) UES data for both the AR application and the traditional slideware presentation from the participants in the Control Group 3) data from the post-study EoC test from both the AR app group and the Control group.

\section{Study results and analysis}

Overall, participants rated the usability of the Augmented reality application highly in PSSUQ questionnaires. For the PSSUQ survey participants were asked to rate their overall

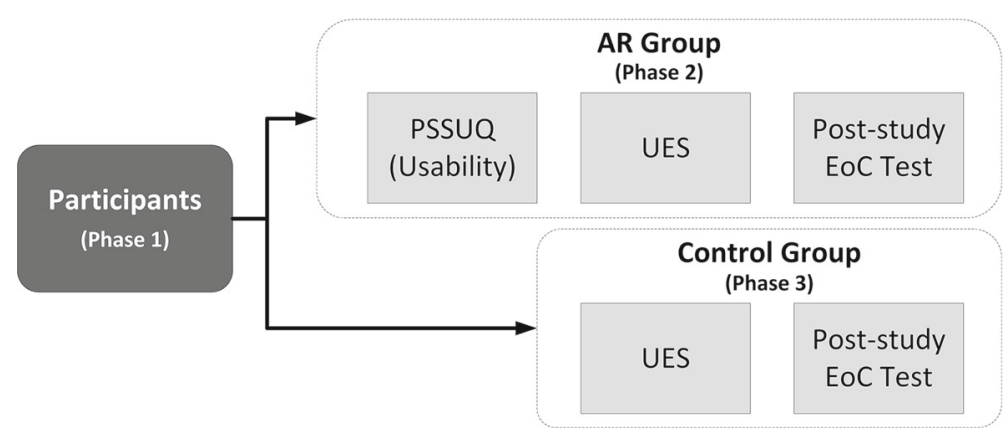

Fig. 7 Summary of the experiment procedure phases, the questionnaires and test taken by the members of AR and Control groups 


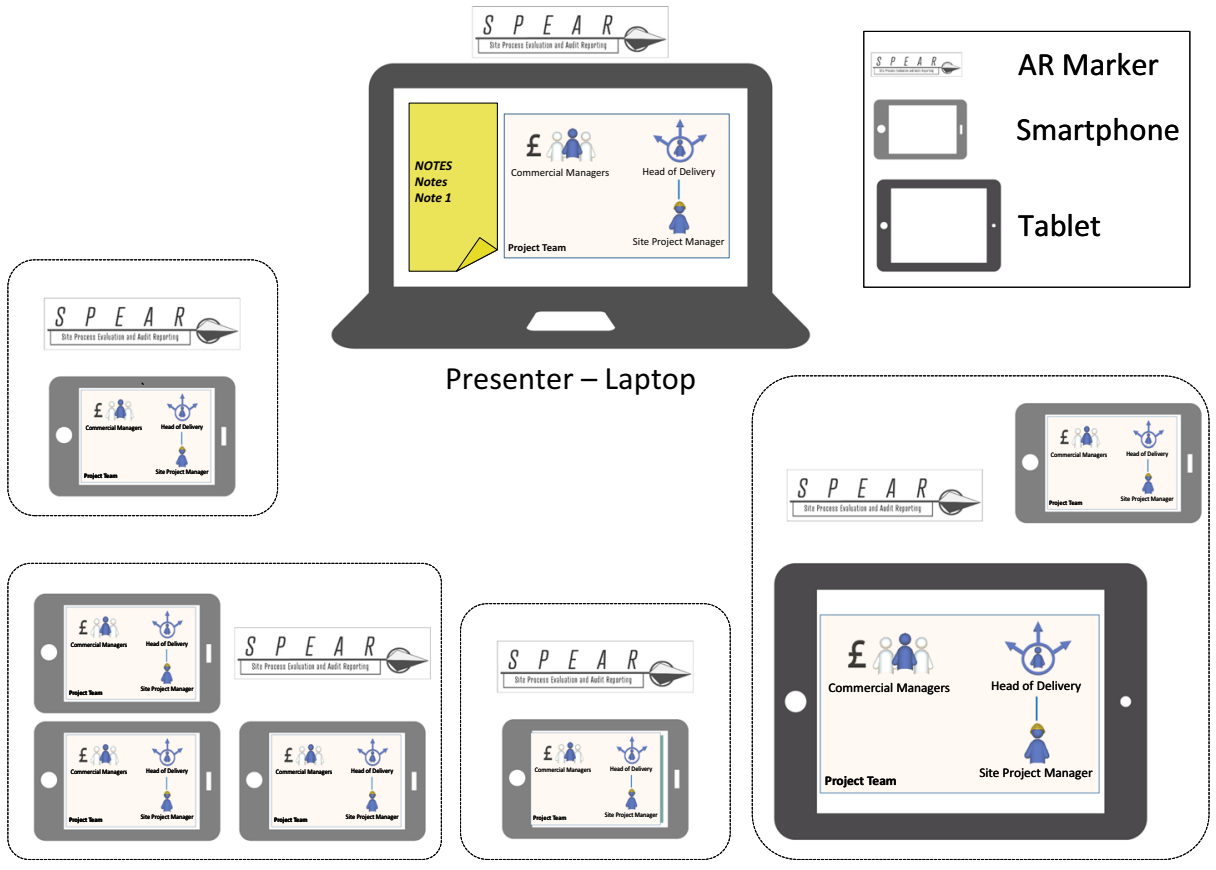

Fig. 8 AR presentation, the room setup, devices used and marker positions

satisfaction of the system in a set of 19 questions on a 7-point Likert-scale (1=strongly disagree to $7=$ strongly agree). Every two answers would provide insight into each of the ten categories (Simplicity, Effective completion of the tasks, comfort, error messages, information, interface, capabilities, overall satisfaction). The mean usability is 100.38 out of 133 $(\mathrm{SD}=14.52)$ which is $75.47 \%$ in percentage. The histogram of participants' mean rating of each of the 19 questions (Fig. 9) shows that the ratings of all participants are above 6 (Agree) which demonstrates that the participants were overall satisfied with the usability of the tool, the information presented, the display of error messages and the efficiency of the process. The reliability analysis [81] of this surveys showed that the Cronbach alpha $(\alpha=$ 0.869 ) is at an acceptable level for this study.

Figure 10 shows the box-plot of the UES surveys for the AR application and the traditional slideware presentations (Control). Participants rated the AR app considerably higher compared to the traditional slideware in the UES survey, suggesting the group who participated in the AR presentation were more engaged compared to the Control group. Table 1 presents the descriptive data of the engagement test between AR application and the Control. As can be observed, the mean of the engagement survey for the AR is higher (158.98) compared to the mean for the Control (47.36).

A Wilcoxon matched pairs signed-rank test [93] was performed to determine whether there is a significant difference in the engagement levels between the group that attended the presentation with the AR application and the control group. The Wilcoxon signed-rank test showed that participants' engagement level was significantly different between the AR group and the Control group $(Z=-5.781, p=0.00)$. The median engagement for the AR app is 156.50 and for the control is 50, suggesting that participants from the AR app group were more engaged compared to the control group. 


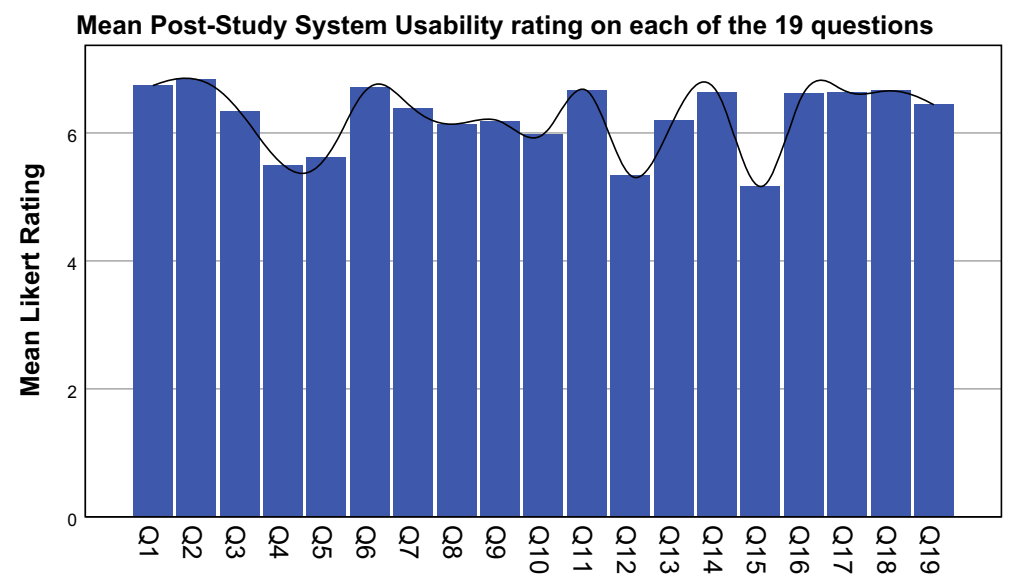

Fig. 9 Histogram of the mean ratings of the PSSUQ survey for the AR app under each of the 19 questions

Existence of any gender differences in usability perception and engagement was also investigated. The Wilcoxon-Mann-Whitney test [25] showed that there is no statistically significant difference between the engagement levels in male and female participants in the AR application $(p=.507)$. Similarly the Wilcoxon-Mann-Whitney test showed no significant difference between the engagement levels in the control group $(p=.453)$. Finally, a

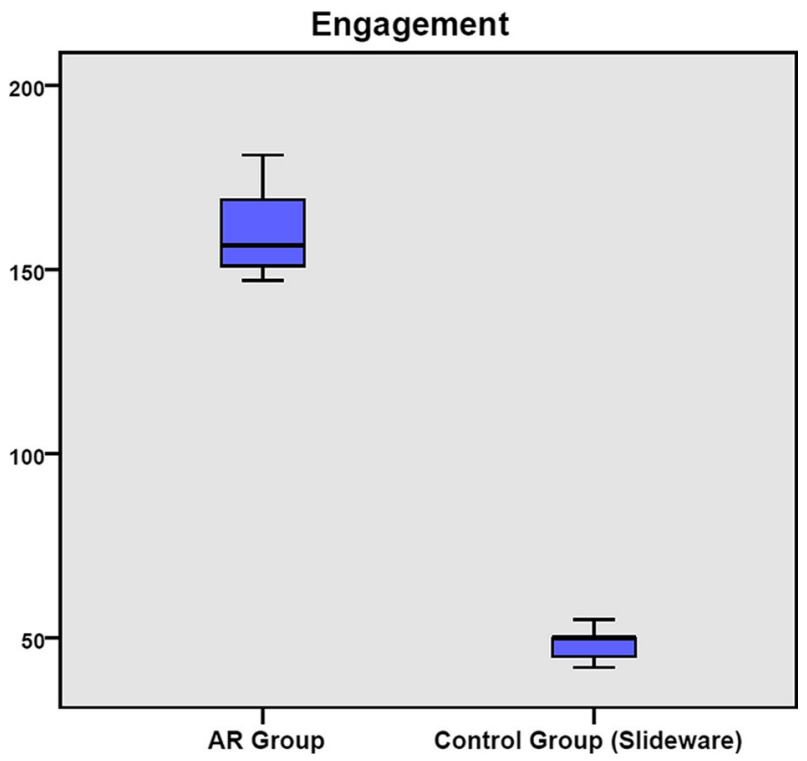

Fig. 10 Box-plot for the overall engagement towards the AR application and the Traditional Slideware in \%, using UES survey 
Table 1 Descriptive data for UES survey comparing engagement between AR and Control

\begin{tabular}{lllllll}
\hline & N & Min & Max & Sum & Mean & SD \\
\hline AR & 48 & 147 & 181 & 7679 & 159.98 & 10.34 \\
Control & 44 & 42 & 55 & 2084 & 47.36 & 3.56 \\
Valid N & 44 & & & & \\
(listwise) & & & & & \\
\hline
\end{tabular}

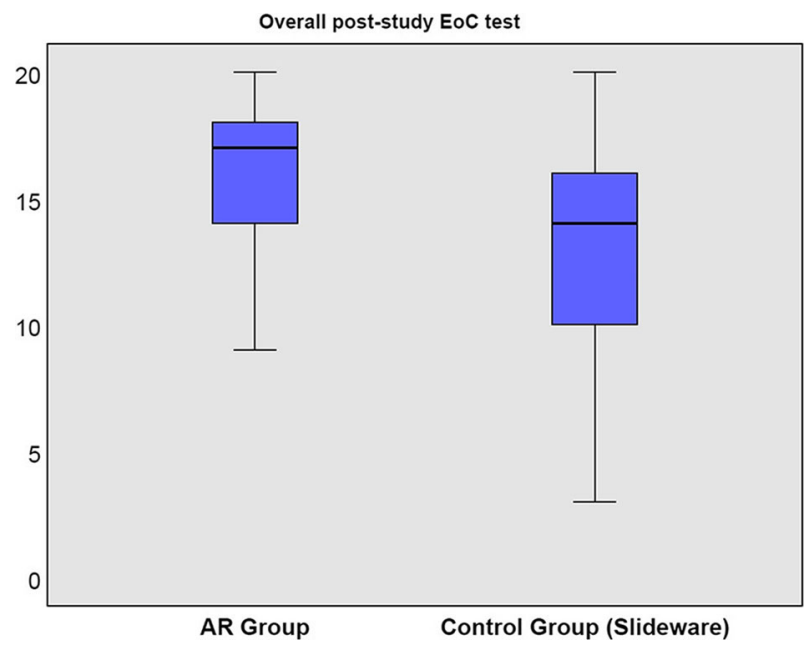

Fig. 11 Box-plot of the overall post-study EoC test for the AR application and the Control group (Traditional Slideware)

Table 2 Descriptive data for the post-study EoC test

\begin{tabular}{lllllll}
\hline & & N & Mean & SD & Min & Max \\
\hline Q1 & AR & 50 & 3.68 & 1.09 & 0 & 4 \\
Q2 & Control & 44 & 3.27 & 1.56 & 0 & 4 \\
& AR & 50 & 2.94 & 0.89 & 0 & 4 \\
Q3 & Control & 44 & 2.41 & 1.04 & 0 & 4 \\
& AR & 50 & 3.16 & 0.842 & 0 & 4 \\
Q4 & Control & 44 & 2.32 & 1.09 & 0 & 4 \\
& AR & 50 & 2.88 & 0.87 & 0 & 4 \\
Q5 & Control & 44 & 2.25 & 1.06 & 0 & 4 \\
& AR & 50 & 3.28 & 1.55 & 0 & 4 \\
& Control & 44 & 3.00 & 1.75 & 0 & 4 \\
& AR & 50 & 15.94 & 2.89 & 9 & 20 \\
& Control & 44 & 13.25 & 4.54 & 3 & 20 \\
\hline
\end{tabular}


Table 3 Summary of Wilcoxon statistics for the post-study EoC test, comparing AR and Control groups

\begin{tabular}{lll}
\hline & $\mathrm{Z}$ & Sig. (2-tailed) \\
\hline Q1 & -1.265 & .206 \\
Q2 & -2.470 & .014 \\
Q3 & -3.035 & .002 \\
Q4 & -2.515 & .012 \\
Q5 & -1.069 & .285 \\
Overall & -2.885 & .004 \\
\hline
\end{tabular}

Kruskal Wallis test [13] was used to determine whether the experience in traditional slideware presentations affected the engagement in the AR app. Kruskal-Wallis H test showed that there was no statistically significant difference in engagement between those who had less experience with presentations and the more experienced $(p=.166)$.

Figure 11 illustrates the box-plot of post-study EoC test which was devised in order to assess the effect of the AR app and its engagement on the Effectiveness of the communication. As can be seen participants in the AR group performed better in the test compared to the participants in the Control group. Table 2 presents the descriptive data of the results between the AR application and the Control group. The mean of the test results in the AR group (15.94) is higher compared to the mean of the Control (13.25).

A Wilcoxon matched pairs signed-rank was performed to determine whether the deference in the test results are statistically significant. The analysis demonstrates that the overall test results from the AR group is significantly higher compared to the Control $(Z=-2.885$, $p=0.004)$. The summary of the Wilcoxon test is presented in Table 3 which demonstrates that the results for the AR group are significantly better compared to Control group over the full test score (overall), and Q2-4. But the results were not significant for Q1 and Q5 which were right/wrong answers. Considering the results it is possible to conclude that the AR presentation was more effective in communicating its content compared to traditional slideware presentations.

\section{Conclusion and discussions}

Presentations are the most successful and popular form of communication in business, however the format of presentations in business has not changed much in the past few decades. The advances in technology, the emergent and disruptive technologies have provided the potential for enhancing communications in businesses, to increase engagement and therefore increase the effectiveness of such communications.

This research has presented a clear advantage to using AR presentations against traditional slideware presentation. Using empirical data, the paper presents a clear improvement in engagement and understanding of participants. This research is confirms the previous efforts by $[7,45,46,59,98]$ through an empirical study using established questionnaires which confirm that using AR for presentations has better usability, and would increase engagement and understanding in users

This paper presented an empirical study into the usability, engagement and effectiveness of using Augmented Reality and Animated infographics in business presentation and compared the results against the traditional slideware presentation approach. In this effect an 
AR application was developed, both for PC and Android devices, which is used for presentations. Both the presenter and the audience members were able to use the app as part of the presentation. An empirical study was then designed and carried out with 94 participants divided into AR group and Control (traditional slideware) group. After the presentation the participants took part in a number of test and standard questionnaires in order to assess the usability of the AR app and then compare the user engagement and effectiveness of communication between the AR presentation and the traditional slideware presentation.

The results of the usability questionnaires (PSSUQ) demonstrated the the app was intuitive and easy to use. Although most participants did not have any prior experience with AR, they were able to quickly learn to use the app effectively.

The results from the engagement questionnaire showed that the participants in the AR group were significantly more engaged with the presentation and found the experience considerably more immersive than traditional presentation. Such response, when using a new technology, could be considered an effect of the novelty of the technology used. In order to assess that the increased engagement had led to a more effective communication, a poststudy test was taken. The results confirmed that the participants in AR group performed better, when quizzed on the content covered during the presentation, compared to the Control group and this difference was statistically significant. Hence, it is possible to conclude that the use of AR in presentations has led to increased audience engagement which in turn has led to a more effective communication.

The findings of this study, although very promising, do not tackle a main challenge in adoption of AR for business presentation which is the overhead for content creation. This challenge consists of two inter-related factors of available tools and knowledge. Currently there are many well-established slideware tools, e.g. PowerPoint, Keynote, etc, that offer intuitive facilities for creating traditional presentations. These tools are widely accessible, relatively affordable, or free, and familiar to majority of people. However, there are not many tools for creation of AR presentations, as proposed here, that can be used without some extent of AR, Unity, 3D and programming knowledge. This makes creating AR presentations expensive, time consuming and expert dependant when compared to existing approaches. There are existing attempts $[62,69]$ towards addressing this challenge which demonstrate promising results yet require further research and dissemination.

Whilst the results presented, demonstrate clear advantage to using AR for business presentations, there are still limitations in the current study that warrant further research. The population size used in the experiment is a clear limitation which requires further studies in order to confirm and generalise the findings. All participants worked for the same company. Therefore, rigour dictates that various other industries and companies should also be part of the study in order to arrive at a solid conclusion. The ease of use for users with less computing acumen also requires further research. Finally, whilst recall has been a good indicator for effectiveness in communication in the context of this experiment, further study is needed to establish the comprehensiveness of understanding in this communication approach.

Open Access This article is licensed under a Creative Commons Attribution 4.0 International License, which permits use, sharing, adaptation, distribution and reproduction in any medium or format, as long as you give appropriate credit to the original author(s) and the source, provide a link to the Creative Commons licence, and indicate if changes were made. The images or other third party material in this article are included in the article's Creative Commons licence, unless indicated otherwise in a credit line to the material. If material is not included in the article's Creative Commons licence and your intended use is not permitted by statutory regulation or exceeds the permitted use, you will need to obtain permission directly from the copyright holder. To view a copy of this licence, visit http://creativecommons.org/licenses/by/4.0/. 


\section{References}

1. Aleokhina A, Tatarnikova I (2017) On some aspects of building business communication competence in english. In: International education social sciences and humanities research conference, pp 294-298

2. Amini F, Henry Riche N, Lee B, Hurter C, Irani P (2015) Understanding data videos: Looking at narrative visualization through the cinematography lens. In: Proceedings of the 33rd Annual ACM conference on human factors in computing systems, pp 1459-1468. ACM

3. Angelini M, Buchmüller J, Keim DA, Meschenmoser P, Santucci G (2019) Surgerycuts: Embedding additional information in maps without occluding features. Comput Graph Forum 38(3):237-247

4. Azuma RT (1997) A survey of augmented reality. Presence Teleoperators Virtual Environ 6(4):355-385

5. Bach B, Sicat R, Beyer J, Cordeil M, Pfister H (2018) The hologram in my hand: How effective is interactive exploration of $3 \mathrm{~d}$ visualizations in immersive tangible augmented reality? IEEE Trans Vis Comput Graph 24(1):457-467

6. Barreiros C, Veas E, Pammer-Schindler V (2016) Pre-attentive features in natural augmented reality visualizations. In: 2016 IEEE international symposium on mixed and augmented reality (ISMAR-Adjunct), pp. 72-73. IEEE

7. Barzuza T, Wiener Y, Modai O (2018) Presentation of enhanced communication between remote participants using augmented and virtual reality. US Patent 9,959,676

8. Bateman J, Wildfeuer J, Hiippala T (2017) Multimodality: Foundations, research and analysis-A problem-oriented introduction. Walter de Gruyter GmbH \& Co KG

9. Bateman S, Mandryk RL, Gutwin C, Genest A, McDine D, Brooks C (2010) Useful junk?: the effects of visual embellishment on comprehension and memorability of charts. In: Proceedings of the SIGCHI conference on human factors in computing systems, pp 2573-2582. ACM

10. Berliner DC (1990) What's all the fuss about instructional time. In: Bromme MBPR (ed) The nature of time in schools: Theoretical concepts, practitioner perceptions, Part, I, chap. 1, pp. 3-35. Teachers College Press

11. Borkin MA, Bylinskii Z, Kim NW, Bainbridge CM, Yeh CS, Borkin D, Pfister H, Oliva A (2016) Beyond memorability: Visualization recognition and recall. IEEE Trans Vis Comput Graph 22(1):519-528

12. Borkin MA, Vo AA, Bylinskii Z, Isola P, Sunkavalli S, Oliva A, Pfister H (2013) What makes a visualization memorable? IEEE Trans Vis Comput Graph 19(12):2306-2315

13. Breslow N (1970) A generalized kruskal-wallis test for comparing k samples subject to unequal patterns of censorship. Biometrika 57(3):579-594

14. Brill JM, Park Y (2008) Facilitating engaged learning in the interaction age taking a pedagogicallydisciplined approach to innovation with emergent technologies. Int J Teach Learn Higher Educ 20(1):70_ 78

15. Brophy JE et al (1982) Relationships between teachers' presentations of classroom tasks and students' engagement in those tasks. Journal of Educational Psychology

16. Cawthon N, Moere AV (2007) The effect of aesthetic on the usability of data visualization. In: 200711 th International conference information visualization (IV'07), pp 637-648. IEEE

17. Chiu CC, Lee CT (2016) Case study of the development app of infographics design with mobile augmented reality. In: 2016 International conference on advanced materials for science and engineering (ICAMSE), pp 181-184. IEEE

18. Dewey J (1913) Interest and effort in education. Houghton Mifflin

19. Dey A, Billinghurst M, Lindeman RW, Swan II JE (2016) A systematic review of usability studies in augmented reality between 2005 and 2014. In: 2016 IEEE international symposium on mixed and augmented reality (ISMAR-Adjunct), pp 49-50. IEEE

20. Dontcheva LA, Drucker S, Cohen MF (2008) Presentation viewing tool designed for the viewer. US Patent 7,383,495

21. Doukianou S, Daylamani-Zad D, Lameras P, Dunwell I (2019) Reinforcing rational decision making in a risk elicitation task through visual reasoning. In: 41st Annual conference of the cognitive science society, pp. 1662-1668

22. Dur BİU, Filipczak-Bialkowska A, Bresciani S, Ge J, Niu Y, Othman A, Wils D (2014) Interactive infographics on the internet. Online Journal of Art and Design 2(4):1-14

23. Edmonds S, Giro A (2018) Activate student engagement: How to promote meaningful learning. In: E-Learn: World conference on e-learning in corporate, government, healthcare, and higher education, pp 807-811. Association for the Advancement of Computing in Education (AACE)

24. Eppler MJ, Burkhard RA (2004) Knowledge visualization-towards a new discipline and its fields of application. Tech. rep. Università della Svizzera italiana

25. Fay MP, Proschan MA (2010) Wilcoxon-mann-whitney or t-test? on assumptions for hypothesis tests and multiple interpretations of decision rules. Statistics surveys 4:1 
26. Fredricks JA, Blumenfeld PC, Paris AH (2004) School engagement: Potential of the concept, state of the evidence. Rev Educ Res 74(1):59-109

27. Fulda J (2018) Interactivity to the rescue. In: Digital investigative journalism, pp 123-135. Springer

28. Gallardo C, Rodríguez SP, Chango IE, Quevedo WX, Santana J, Acosta AG, Tapia JC, Andaluz VH (2018) Augmented reality as a new marketing strategy. In: International conference on augmented reality, virtual reality and computer graphics, pp. 351-362. Springer

29. Gehman HW (2003) Columbia accident investigation board report, vol. 6 Columbia Accident Investigation Board

30. Good L, Bederson BB (2001) Counterpoint: Creating jazzy interactive presentations. Tech. rep., UMIACS

31. Good LE, Bederson BB, Stefik MJ (2010) Methods and systems for supporting presentation tools using zoomable user interface. US Patent 7,707,503

32. Gribok MV (2015) Video infographics for sustainable development-the example of the Russia in figures project. Tech. rep., Lomonosov Moscow State University

33. Harrison L, Reinecke K, Chang R (2015) Infographic aesthetics: Designing for the first impression. In: Proceedings of the 33rd Annual ACM conference on human factors in computing systems, pp 11871190. ACM

34. Ivanov A, Danyluk K, Jacob C, Willett W (2019) A walk among the data. IEEE Comput Graph Appl 39(3):19-28

35. Ivson P, Nascimento D, Celes W, Barbosa SD (2017) Cascade: a novel 4d visualization system for virtual construction planning. IEEE Trans Vis Comput Graph 24(1):687-697

36. Kernbach S, Eppler MJ (2010) The use of visualization in the context of business strategies: an experimental evaluation. In: 2010 14th International conference information visualisation, pp 349-354. IEEE

37. Khan M, Khan SS (2011) Data and information visualization methods, and interactive mechanisms: A survey. Int J Comput Appl 34(1):1-14

38. Khan-Panni P (2012) FT Essential guide to making business presentations: How to deliver a winning message. Pearson UK

39. Kosara R, Mackinlay J (2013) Storytelling: The next step for visualization. Computer 46(5):44-50

40. Kosslyn SM, Kievit RA, Russell AG, Shephard JM (2012) Powerpoint ${ }^{\circledR}$ presentation flaws and failures: a psychological analysis. Front Psychol 3:230

41. Lengler R, Moere AV (2009) Guiding the viewer's imagination: How visual rhetorical figures create meaning in animated infographics. In: 2009 13th International conference information visualisation, pp 585-591. IEEE

42. Lentz FE (1988) On-task behavior, academic performance, and classroom disruptions: Untangling the target selection problem in classroom interventions. School Psychology Review

43. Lewis C, Rieman J (1993) Task-centered user interface design. A practical introduction

44. Lewis JR (2002) Psychometric evaluation of the pssuq using data from five years of usability studies. Int J Human-Comput Interact 14(3-4):463-488

45. Liarokapis F, Anderson EF (2010) Using augmented reality as a medium to assist teaching in higher education. In: Eurographics 2010, pp 9-16. Eurographics Association

46. Liarokapis F, Mourkoussis N, White M, Darcy J, Sifniotis M, Petridis P, Basu A, Lister PF (2004) Web3d and augmented reality to support engineering education. World Trans Eng Technol Educ 3(1):11-14

47. Lievemaa J (2017) Animated infographics in digital educational publishing: Case study of educational animated infographics. Master's thesis, Tampere University of Applied Sciences

48. Lipkus IM, Hollands JG (1999) The visual communication of risk. J Natl Cancer Inst Monographs 1999(25):149-163

49. Locoro A, Cabitza F, Actis-Grosso R, Batini C (2017) Static and interactive infographics in daily tasks: A value-in-use and quality of interaction user study. Comput Hum Behav 71:240-257

50. Lyra KT, Isotani S, Reis RC, Marques LB, Pedro LZ, Jaques PA, Bitencourt II (2016) Infographics or graphics+ text: which material is best for robust learning? In: 2016 IEEE 16th International conference on advanced learning technologies (ICALT), pp 366-370. IEEE

51. McMahon B, Portelli JP (2004) Engagement for what? beyond popular discourses of student engagement. Leadership and Policy in Schools 3(1):59-76

52. Meece JL, Blumenfeld PC, Hoyle RH (1988) Students' goal orientations and cognitive engagement in classroom activities. J Educ Psychol 80(4):514

53. Meeusah N, Tangkijviwat U (2013) Effect of data set and hue on a content understanding of infographic. Tech. rep., Rajamangala University of Technology Thanyaburi Faculty of Mass Communication Technology 
54. Meiguins BS, do Carmo RC, Goncalves AS, Godinho PIA, de Brito Garcia M (2006) Using augmented reality for multidimensional data visualization. In: Tenth international conference on information visualisation (IV'06), pp 529-534. IEEE

55. Meiguins BS, do Carmo RMC, Almeida L, Gonçalves AS, Pinheiro SCV, de Brito Garcia M, Godinho PIA (2006) Multidimensional information visualization using augmented reality. In: Proceedings of the 2006 ACM international conference on virtual reality continuum and its applications, pp 391-394. ACM

56. Milatz M (2013) Moving graphics: The effects of interactive infographics on media users' recall accuracy. Master's thesis, Aarhus

57. Moon J (2007) How to Make an Impact: Influence, inform and impress with your reports, presentations and business documents pearson education

58. Neumeier M (2009) The Designful Company: How to build a culture of nonstop innovation. Peachpit Press

59. Novotnỳ M, Lacko J, Samuelčík M (2013) Applications of multi-touch augmented reality system in education and presentation of virtual heritage. Procedia Comput Sci 25:231-235

60. O'Connell A, Mecham C et al (2019) Creative collaboration: Enhancing meaningful learning. Independence 44(1):38

61. Oh YJ, Park KW, Kim EK (2015) Efficient 3d design drawing visualization based on mobile augmented reality. In: 2015 17th International conference on advanced communication technology (ICACT), pp 568-573. IEEE

62. Pagés R., Amplianitis K, Monaghan D, Ondřej J, Smolić A (2018) Affordable content creation for freeviewpoint video and vr/ar applications. J Vis Commun Image Represent 53:192-201

63. Pantile D, Frasca R, Mazzeo A, Ventrella M, Verreschi G (2016) New technologies and tools for immersive and engaging visitor experiences in museums: The evolution of the visit-actor in next-generation storytelling, through augmented and virtual reality, and immersive 3d projections. In: 2016 12th International conference on signal-image technology \& internet-based systems (SITIS), pp 463-467. IEEE

64. Parry H (1991) Successful Business Presentations. Croner Publications Ltd

65. Pastizzo MJ, Erbacher RF, Feldman LB (2002) Multidimensional data visualization. Behav Res Methods Instrum Comput 34(2):158-162

66. Pintrich PR, De Groot EV (1990) Motivational and self-regulated learning components of classroom academic performance. J Educ Psychol 82(1):33

67. Platts K, Hua Tan K (2004) Strategy visualisation: knowing, understanding, and formulating. Manag Dec 42(5):667-676

68. Plowman L, Luckin R, Laurillard D, Stratfold M, Taylor J (1999) Designing multimedia for learning: Narrative guidance and narrative construction. In: Proceedings of the SIGCHI conference on human factors in computing systems, pp 310-317. ACM

69. Puggioni MP, Frontoni E, Paolanti M, Pierdicca R, Malinverni ES, Sasso M (2020) A content creation tool for ar/vr applications in education: The scoolar framework. In: International conference on augmented reality, virtual reality and computer graphics, pp 205-219. Springer

70. Rahim NN, Khidzir NZ, Yusof AM, Daud KAM (2015) Towards a conceptual framework of animated infographics in an islamic contect. In: Proceeding of 1st international islamic heritage conference. Universiti Teknologi Mara, Melaka, pp 38-47

71. Resnikoff HL (1989) True-focus bifocal eyeglasses. US Patent 4,830,482

72. Reynolds G (2014) Presentation Zen Design: A Simple Visual Approach to Presenting in Today's World. Pearson Education

73. Robertson G, Fernandez R, Fisher D, Lee B, Stasko J (2008) Effectiveness of animation in trend visualization. IEEE Trans Vis Comput Graph 14(6):1325-1332

74. Robertson GG, Card SK, Mackinlay JD (1993) Information visualization using 3d interactive animation. Commun ACM 36(4):56-72

75. Robertson GG, Mackinlay JD, Card S (1991) The perspective wall: Detail and context smoothly integrated. In: Proceedings of ACM CHI, vol. 91, pp. 173-179

76. Roman K, Raphaelson J (2000) Writing for an Audience: Presentations and Speeches, chap. 6, pp. 90 111 Harper Collins

77. Shaw G, Brown R, Bromiley P (1998) Strategic stories: how $3 \mathrm{~m}$ is rewriting business planning. Harvard Business Rev 76(3):41-2

78. Skinner EA, Belmont MJ (1993) Motivation in the classroom: Reciprocal effects of teacher behavior and student engagement across the school year. J Educ Psychol 85(4):571

79. Stone $M$ (2006) Choosing colors for data visualization. Business Intelligence Network 2

80. Swan JE, Gabbard JL (2005) Survey of user-based experimentation in augmented reality. In: Proceedings of 1st international conference on virtual reality, vol 22, pp 1-9 
81. Tavakol M, Dennick R (2011) Making sense of cronbach's alpha. Int J Med Educ 2:53

82. Thomas BH, Marner M, Smith RT, Elsayed NAM, Von Itzstein S, Klein K, Adcock M, Eades P, Irlitti A, Zucco J et al (2014) Spatial augmented reality—a tool for 3d data visualization. In: 2014 IEEE VIS international workshop on 3DVis (3DVis), pp 45-50. IEEE

83. Tominski C, Gladisch S, Kister U, Dachselt R, Schumann H (2017) Interactive lenses for visualization: An extended survey. Comput Graph Forum 36(6):173-200

84. Tufte ER (2003) The cognitive style of powerpoint: Pitching out corrupts within

85. Unity Technologies: Multiplayer and Networking. https://docs.unity3d.com/Manual/UNet.html. Accessed: 2020-04-16

86. Unity Technologies: Unity. https://unity3d.com/. Accessed: 2020-04-16

87. Vuforia: Vuforia: Market-leading enterprise AR. https://www.vuforia.com/. Accessed: 2020-04-16

88. Wagner DN (2017) Bulletproof from delivery to interactivity when teaching with powerpoint. Int J Innov Educ 4(1):16-31

89. Wang YC, Zhang Q, Lin F, Goh CK, Seah HS (2019) Polarviz: a discriminating visualization and visual analytics tool for high-dimensional data. Vis Comput 35(11):1567-1582

90. Ware C (2012) Information visualization: perception for design. Elsevier, Amsterdam

91. Ware C (2019) Information visualization: perception for design. Morgan Kaufmann

92. Wiebe EN, Lamb A, Hardy M, Sharek D (2014) Measuring engagement in video game-based environments: Investigation of the user engagement scale. Comput Hum Behav 32:123-132

93. Wilcoxon F (1992) Individual comparisons by ranking methods. In: Breakthroughs in statistics, pp. 196-202. Springer

94. Williams R (2017) The non-designer's presentation book: principles for effective presentation design. Peachpit Press

95. Winn W (1991) Learning from maps and diagrams. Educ Psychol Rev 3(3):211-247

96. Yang KJ, Chu HC, Yang KH (2015) Using the augmented reality technique to develop visualization mindtools for chemical inquiry-based activities. In: 2015 IIAI 4th International congress on advanced applied informatics, pp 354-357. IEEE

97. Zhang X, Navab N, Liou SP (2000) E-commerce direct marketing using augmented reality. In: 2000 IEEE International conference on multimedia and expo. ICME2000. proceedings. latest advances in the fast changing world of multimedia (Cat. No. 00TH8532), vol. 1, pp. 88-91. IEEE

98. Zoellner M, Keil J, Wuest H, Pletinckx D (2009) An augmented reality presentation system for remote cultural heritage sites. In: Proceedings of the 10th international symposium on virtual reality, archaeology and cultural heritage VAST, pp. 112-116. Citeseer

Publisher's note Springer Nature remains neutral with regard to jurisdictional claims in published maps and institutional affiliations. 